\title{
Studi Eksperimental Efektivitas Pijat dengan Minyak Esensial Cengkeh terhadap Status Fungsional Pasien Osteoartritis
}

\author{
Dewi Puspita Apsari dan Ni Luh Setiawati
}

\author{
Program Studi Farmasi Klinis, Fakultas Ilmu-IImu Kesehatan, Universitas Bali, Bali, Indonesia \\ Korespondensi: Dewi Puspita Apsari \\ Email: dewipuspitaapsari@gmail.com
}

Submitted : 16-11-2020, Revised : 23-12-2020, Accepted : 12-06-2021

\begin{abstract}
ABSTRAK: Pengobatan konvensional seperti NSAID sering digunakan untuk mengontrol nyeri dan inflamasi pasien osteoartritis (OA). Namun terkadang obat tersebut tidak efektif. Kombinasi pengobatan konvensional dan pelayanan kesehatan tradisional dirasa mampu mengatasi masalah tersebut. Tujuan penelitian ini adalah untuk mengetahui efektivitas pijat dengan minyak esensial cengkeh terhadap status fungsional pasien OA. Metode yang digunakan adalah quasi experimental-nonequivalent control group design pada 40 pasien OA yang berusia 46-84 tahun dengan skor VAS>4. Pada kelompok intervensi, pasien OA diberikan kombinasi terapi konvensional dan pijat dengan minyak esensial cengkeh. Sebaliknya pada kelompok kontrol pasien OA diberikan kombinasi terapi konvensional dan pijat dengan minyak kelapa. Penilaian efektivitas dilakukan pada hari ke-0, 1, 2 dan 3 pengobatan dengan kuisoner WOMAC (Western Ontario and McMaster Universities Osteoarthritis index). Status fungsional pasien digambarkan dalam empat skor outcome yakni skor total WOMAC, intensitas nyeri, kekakuan, dan fungsi fisik pasien. Hasil penelitian menunjukkan bahwa pijat dengan minyak esensial cengkeh signifikan meningkatkan status fungsional pasien dengan nilai rata-rata skor total WOMAC $(21,30 \pm 3,36 ; p=0,02)$, nyeri $(3,80 \pm 1,01 ; p=0,00)$, kekakuan $(1,85 \pm 0,75 ; p=0,00)$ dan domain fungsi fisik $(15,65 \pm 2,54 ; \mathrm{p}=0,00)$ di hari ketiga pengobatan. Sebaliknya kelompok kontrol hanya signifikan menurunkan intensitas nyeri $(7,60 \pm 1,73 ; p=0,00)$ yang dialami pasien. Jadi kombinasi pengobatan konvensional dan pijat dengan minyak esensial cengkeh meningkatkan status fungsional pasien OA.
\end{abstract}

Kata kunci: fungsi fisik; kekakuan; minyak esensial cengkeh; nyeri; osteoartritis

\begin{abstract}
Conventional therapy such as NSIDs are used to control pain dan inflammation osteoarthritis (OA). However, sometimes these medicines are not effective. Combination of conventional therapy and Complementery Alternative Medicine (CAM) is able to overcome this problem. The purpose of this study was to assess the effectiveness massage with clove essential oil on functional status OA patients. Forty osteoarthritis patients, aged 46-84 years with VAS score $>4$, were enrolled in quasi experimental-nonequivalent control group designstudy. In the intervention group, OA patients were given conventional therapy and massage with clove essential oil. The placebo control group received the same conventional therapy with coconut oil only. Assessment were carried out on days 0, 1, 2 and 3 of treatment with WOMAC (Western Ontario and McMaster Universities Osteoarthritis index). The functional status of the patients described in four outcomes, there are global WOMAC, pain intensity, stiffness, and patient physical function. The group receiving massage with clove essential oil demonstrated significant improvements in the WOMAC total scores (21.30 \pm 3.36 ; $p=0.02)$, pain (3.80 \pm 1.01 , $p=0,00)$, stiffness $(1.85 \pm 0.75, p=0.00)$ and physical function domains $(15.65 \pm 2.54, p=0.00)$ after three days of treatment. However, control group only significant in pain scores ( $7.60 \pm 1.73, p=0.00)$. In conclussion, combination of conventional therapy and massage with clove essential oil improve functional status of OA patients.
\end{abstract}

Keywords: Clove Essential Oil; osteoarthritis; pain; physical function; stiffness 


\section{Pendahuluan}

Pelayanan kesehatan tradisional (yankestrad) telah diakui keberadaannya sejak dahulu kala dan dimanfaatkan oleh masyarakat dalam upaya preventif, promotif, kuratif, dan rehabilitatif [1]. Berdasarkan data Riskesdas (2018), sebanyak 31,4\% penduduk Indonesia telah memanfaatkan yankestrad. Yankestrad tersebut mencakup ramuan jadi (48\%), ramuan buatan sendiri $(31,8 \%)$, keterampilan manual $(65,3 \%)$, keterampilan olah pikir (1,9\%), dan keterampilan energi $(2,1 \%)$ [2]. Jadi keterampilan manual menduduki urutan tertinggi yankestrad yang digunakan oleh penduduk Indonesia. Menurut penelitian Kadir (2018), penggunaan yankestrad pada pasien osteoartritis (OA) di dunia berkisar 40-64,8\% [3]. Alasan terbesar penggunaan yankestrad adalah pasien merasa frustasi dengan pengobatan konvensional yang didapat dan persepsi akan amannya menggunakan yankestrad [4]. Akibat tingginya penggunaan yankestrad terutama keterampilan manual di Indonesia, maka penting untuk menyediakan informasi yang akurat mengenai efektivitas terapi tersebut pada pasien OA dan dokter.

OA merupakan penyakit yang mengakibatkan degenerasi tulang rawan dan deformitas sendi, akibatnya pasien akan merasakan nyeri dan hal ini akan menurunkan kualitas hidup pasien. Berbagai studi melaporkan, terdapat hubungan yang signifikan keparahan OA terhadap status fungsional pasien [5]. Hingga saat ini, pedoman terapi yang ada merekomendasikan terapi konvensional farmakologis dan non-farmakologis untuk mengatasi masalah tersebut [6]. Terapi non-farmakologis seperti edukasi, latihan, dan penurunan berat badan memiliki kelemahan yakni kurang banyak digunakan dan tidak dapat mengontrol keluhan pasien jika gejala penyakit semakin parah. Terapi farmakologi bertujuan untuk mengontrol gejala yang dialami pasien. Nonsteroidalanti-inflammatory drugs (NSAID) dan parasetamol merupakan terapi farmakologi yang paling banyak digunakan untuk mengontrol nyeri pasien OA [3]. Walaupun dokter menyarankan terapi tersebut, akan tetapi pengobatan tersebut efektivitasnya terbatas dan memiliki efek samping [7].

Pada pasien lansia, terapi farmakologis tidak cukup mengontrol nyeri yang dialami pasien OA. Hal tersebut disebabkan penyakit penyerta yang dimiliki dan interaksi obat yang terjadi akibat banyaknya obat yang dikonsumsi. Oleh karena itu diperlukan suatu pengobatan yang tidak mahal, mampu diaplikasikan sendiri, tidak toksik, dan alami yang mampu mengontrol gejala OA [8]. Kombinasi terapi konvensional dan keterampilan manual seperti pijat mampu menjawab permasalahan tersebut [9]. Terapi pijat menunjukkan efek positif dalam menurunkan nyeri otot [10]. Penelitian Field et al. (2005), membuktikan pijat dapat meningkatkan hormon endorfin, peningkatan neurotransmitter serotonin dan dopamin, serta meningkatkan aliran darah sehingga rangsangan nyeri dapat dihentikan [11].

Pijat tidak sepenuhnya dapat mengontrol nyeri yang dialami oleh pasien [12]. Oleh karena itu Osborn et al. (2001), menyarakankan adanya penambahan minyak esensial untuk memperpanjang efek dari pijat yang diberikan [13]. Penelitian yang dilakukan Palupi (2016) membuktikan bahwa pengolesan minyak esensial cengkeh (Caryophyllus aromaticus L.) signifikan ( $\mathrm{p}=0,000)$ menurunkan nyeri sendi yang dialami oleh 25 pasien lansia [9], namun belum ada data bagaimana pengaruh minyak esensial cengkeh terhadap status fungsional pasien OA. Oleh karena itu perlu dilakukan penelitian lebih lanjut mengenai efektivitas kombinasi pengobatan konvensional dan pijat dengan minyak esensial cengkeh terhadap status fungsional pasien $\mathrm{OA}$.

\section{Metode}

\subsection{Bahan penelitian}

Bahan yang digunakan adalah minyak esensial cengkeh 5\% untuk kelompok intervensi dan minyak kelapa untuk kelompok kontrol (Utama 
Spice, yang diproduksi oleh PT. Supa Dupa Spice).

\subsection{Rancangan penelitian}

Rancangan penelitian yang digunakan adalah quasi experimental-nonequivalent control group design. Penelitian yang dilakukan telah memperoleh ijin kelaikan kode etik dari Komisi Etik Penelitian (KEP) Fakultas Kedokteran Universitas Udayana dengan Nomor: 812/ UN14.2.2.VII.14/LT/2020. Subjek dalam penelitian ini adalah pasien OA di Puskesmas yang berusia 46-84 tahun dan mengalami nyeri dengan derajat sedang hingga berat (skor VAS >4). Subjek yang dieksklusi pada penelitian adalah subjek yang tidak menyukai dan alergi terhadap minyak esensial cengkeh, mengalami operasi lutut dalam waktu 3 bulan terakhir, melakukan fisioterapi untuk mengatasi nyeri lutut akibat OA, mendapatkan injeksi steroid, memiliki luka besar pada area lutut dan memiliki gejala inflamasi akut pada lutut akibat OA. Rumus slovin digunakan dalam menghitung jumlah sampel yang dibutuhkan. Jumlah sampel yang diperlukan masing-masing kelompok adalah 20 orang. Menurut literatur, jumlah sampel tersebut mampu memberikan medium effect size $(\mathrm{f}=0,5)$ dengan power $90 \%$ dan $\alpha=0,05$ [14], sehingga total sampel yang dibutuhkan adalah 40 orang. Teknik pengambilan sampel yang digunakan adalah purposive sampling.

Terdapat 2 kelompok sampel pada penelitian ini yakni kelompok intervensi dan kelompok kontrol. Pada kelompok intervensi, pasien OA diberikan pijat $\pm 5-10$ menit dengan minyak esensial cengkeh 3-5 tetes satu kali sehari saat pagi hari. Selanjutnya pasien dapat mengkonsumsi pengobatan konvensional yang diberikan dokter di Puskesmas. Pada kelompok kontrol, pasien OA hanya diberikan pijat \pm 5 10 menit dengan minyak kelapa satu kali sehari saat pagi hari. Selanjutnya pasien dapat mengkonsumsi pengobatan konvensional yang diberikan dokter di Puskesmas. Hal ini dilakukan selama 3 hari berturut-turut. Outcome pada penelitian ini yakni status fungsional pasien yang digambarkan pada skor total WOMAC, skor intensitas nyeri, skor kekakuan, dan skor fungsi fisik pasien OA. Outcome diukur pada hari ke-0, 1, 2, dan 3 pengobatan.

Instrumen pengukuran status fungsional pasien adalah kuesioner WOMAC (Western Ontario and McMaster Universities Osteoarthritis index). Kuesioner ini terdiri dari 24 pertanyaan yang mencakup 5 pertanyaan mengenai nyeri, 2 pertanyaan mengenai kekakuan, dan 17 pertanyaan mengenai fungsi fisik. Lima poin skala likert ( 0 =tidak, 1 =ringan, $2=$ sedang, 3=berat, 4=sangat berat) digunakan dalam skoring. Nilai skor untuk masing-masing bagian yakni nyeri (0-20), kekakuan (0-8), fungsi fisik (0-68) dan skor total WOMAC (0-96). Semakin tinggi nilai yang diperoleh menunjukkan semakin besar keterbatasan fungsional pasien, sedangkan nilai yang rendah menunjukkan perbaikan kemampuan fungsional. Interpretasi skor total WOMAC adalah ringan (0-24), sedang (25-48), berat (49-72), dan sangat berat (73-96).

\subsection{Analisis data}

Teknik analisis data menggunakan analisis univariat dan bivariat. Analisis univariat dengan statistik deskriptif pada karakteristik responden yang mencakup jenis kelamin, usia, indeks masa tubuh, obat nyeri yang dikonsumsi, vitamin yang dikonsumsi, obat herbal yang dikonsumsi, riwayat nyeri osteoartritis, nyeri lutut yang dialami, nilai rata-rata (SD) skor total WOMAC, skor intensitas nyeri, skor kekakuan, dan skor fungsi fisik pasien OA. Analisis bivariat dengan U Mann Whitney dilakukan untuk menguji perbedaan kelompok intervensi dan kelompok kontrol terhadap karakteristik responden, skor total WOMAC, skor intensitas nyeri, skor kekakuan, dan skor fungsi fisik pasien $\mathrm{OA}$.

\section{Hasil dan pembahasan}

3.1. Karakteristik responden 
Sebanyak 40 responden berhasil menyelesaikan penelitian yang dilakukan pada hari ketiga pengobatan (Gambar 1). Tidak ada responden yang loss of follow up. Mayoritas 40 responden yang diteliti adalah perempuan (66\%) dan berusia 59-71 tahun (58\%) sesuai dengan Tabel 1. Sebagian besar responden memiliki riwayat nyeri osteoartritis 1-3 tahun (60\%) serta nyeri lutut terutama bagian kaki kanan tubuh (65\%). Tiga puluh tujuh responden (92\%) mengkonsumsi analgesik natrium diklofenak dan 40 pasien $(100 \%)$ diberikan vitamin B-kompleks dan tidak sedang mengkonsumsi obat herbal. Indeks masa tubuh responden sebanyak 15 (38\%) orang termasuk ke dalam overweight dengan risiko. Selain itu juga sebagian besar responden mengeluhkan nyeri lutut pada bagian kanan yakni sebesar 26 (65\%). Pada sebagian besar responden yang diteliti tidak terdapat perbedaan signifikan antara kelompok intervensi dan kelompok kontrol ( $p=0,19-1,00)$ kecuali pada karakteristik riwayat mengalami nyeri OA yakni terdapat perbedaan signifikan $(p=0,01)$ antara kelompok intervensi dan kelompok kontrol. Jadi kedua kelompok yang diteliti tidak homogen.

\subsection{Efektivitas pemberian minyak esensial cengkeh terhadap status fungsional pasien osteoartritis}

Cengkeh merupakan tumbuhan yang sering dimanfaatkan sebagai aromaterapi. Zat aktif yang terdapat dalam cengkeh adalah eugenol yang memiliki aktivitas antioksidan, analgesik, anti inflamasi, dan anti mikroba [15]. Pengaplikasian minyak esensial cengkeh pada kulit dapat menimbulkan efek vasodilatasi atau pelebaran pembuluh darah sehingga terjadi peningkatan relaksasi otot yang menyebabkan adanya penurunan sensasi nyeri akibat kekakuan [16]. Hingga saat ini belum ada bukti ilmiah mengenai efektivitas kombinasi pengobatan konvesional dengan pijat menggunakan minyak esensial cengkeh terhadap status fungsional pasien OA.

Penilaian status fungsional pasien $\mathrm{OA}$ dilakukan dari tiga parameter yakni skor total WOMAC, intensitas nyeri, kekakuan, dan fungsi

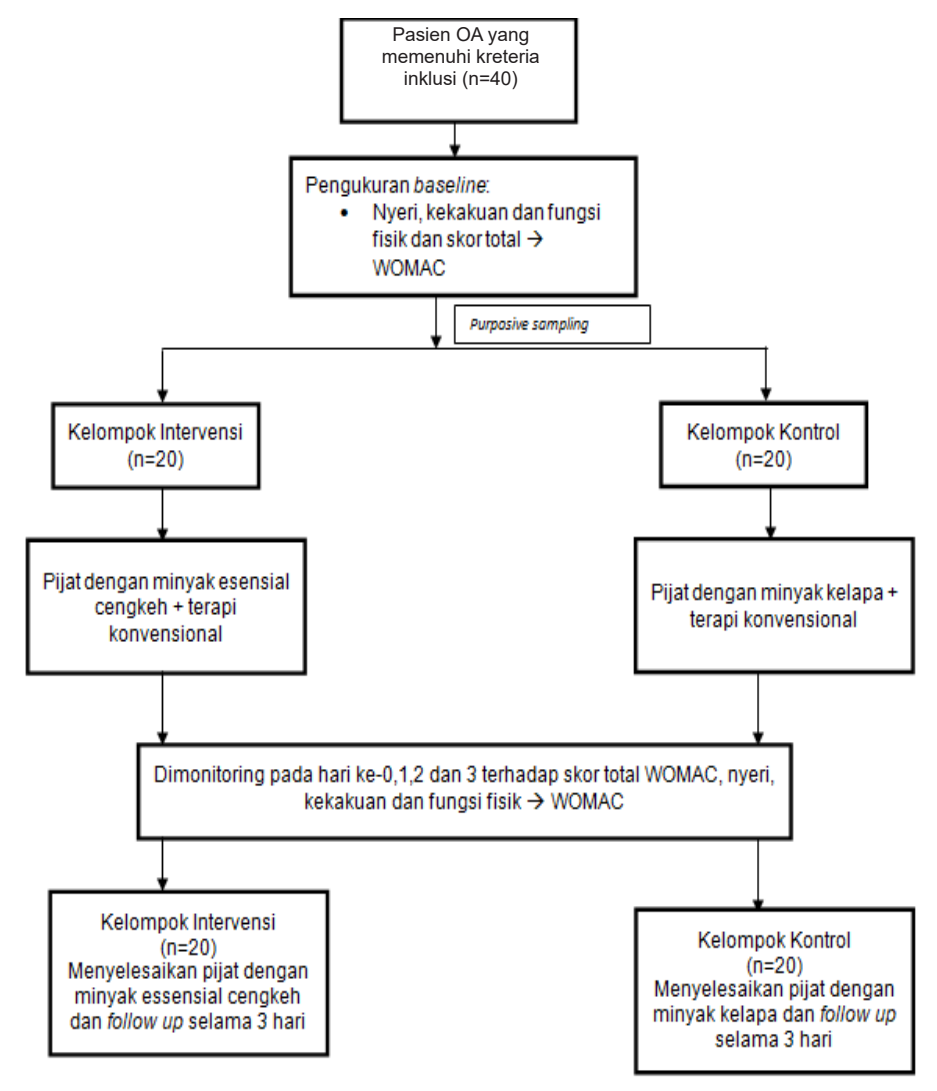

Gambar 1. Profil subjek yang dilibatkan dalam penelitian 
Tabel 1. Data karakteristik responden

\begin{tabular}{|c|c|c|c|}
\hline Karakteristik & $\begin{array}{l}\text { Kelompok kontrol } \\
\text { n (\%) }\end{array}$ & $\begin{array}{l}\text { Kelompok intervensi } \\
\text { n (\%) }\end{array}$ & p-value \\
\hline \multicolumn{4}{|l|}{ Jenis kelamin } \\
\hline a. Laki-laki & $7(17)$ & $7(17)$ & 1,00 \\
\hline b. Perempuan & $13(33)$ & $13(33)$ & \\
\hline \multicolumn{4}{|l|}{ Usia } \\
\hline a. 59 tahun & $4(10)$ & $11(28)$ & 0,19 \\
\hline b. 59-71 tahun & $15(38)$ & $8(20)$ & \\
\hline c. $>71$ tahun & $1(2)$ & $1(2)$ & \\
\hline \multicolumn{4}{|l|}{ Indeks masa tubuh } \\
\hline a. Normal & $3(8)$ & $5(12)$ & 1,00 \\
\hline b. Overweight dengan obesitas I & $9(22)$ & $4(10)$ & \\
\hline c. Overweight dengan obesitas II & $0(0)$ & $4(10)$ & \\
\hline d. Overweight dengan resiko & $8(20)$ & $7(18)$ & \\
\hline \multicolumn{4}{|l|}{ Obat nyeri yang dikonsumsi } \\
\hline a. Natrium diklofenak & $17(42)$ & $20(50)$ & 1,00 \\
\hline b. Asam mefenamat & $3(8)$ & $0(0)$ & \\
\hline \multicolumn{4}{|l|}{ Vitamin yang dikonsumsi } \\
\hline a. Vitamin B Komplek & $20(50)$ & $20(50)$ & 1,00 \\
\hline \multicolumn{4}{|l|}{ Obat herbal yang dikonsumsi } \\
\hline a.Tidak mengkonsumsi obat herbal & $20(50)$ & $20(50)$ & 1,00 \\
\hline b. Mengkonsumsi obat herbal & $0(0)$ & $0(0)$ & \\
\hline \multicolumn{4}{|l|}{ Riwayat nyeri ostheoartritis } \\
\hline a. $<1$ tahun & $12(30)$ & $4(10)$ & 0,01 \\
\hline b. 1-3 tahun & $8(20)$ & $16(40)$ & \\
\hline \multicolumn{4}{|l|}{ Nyeri lutut yang dialami } \\
\hline a. Bilateral & $2(5)$ & $2(5)$ & 0,39 \\
\hline b. Unilateral kiri & $6(15)$ & $4(10)$ & \\
\hline c. Unilateral kanan & $12(30)$ & $14(35)$ & \\
\hline
\end{tabular}

fisik pasien. Hasil uji karakteristik baseline pada skor total WOMAC, nyeri, kekakuan dan fungsi fisik menunjukkan kedua kelompok tidak homogen dengan nilai signifikansi 0,00-0,04. Pada Tabel 2 terlihat bahwa pada kelompok intervensi terjadi penurunan signifikan $(p=0,02)$ skor baseline total WOMAC yakni dari 46,55 $\pm 4,71$ menjadi $21,30 \pm 3,36$ di hari ketiga pengobatan. Data tersebut menunjukkan pijat dengan minyak esensial cengkeh mampu meningkatkan status fungsional pasien dimana status fungsional pasien yang semula sedang menjadi ringan. Hal sebaliknya terjadi pada kelompok kontrol yakni tidak terdapat perbedaan signifikan $(p=1,00)$ skor baseline total WOMAC yakni dari 40,95 \pm 7,68 menjadi 40,35 $\pm 7,53$ pada hari ketiga pengobatan. Jadi pijat dengan minyak kelapa tidak mengubah status fungsional pasien, dimana status fungsional pasien tetap sedang. Dari penelitian ini terlihat bahwa pijat dengan minyak esensial cengkeh memiliki potensi alternatif untuk meredakan nyeri lutut secara cepat pada pasien OA.

Pada Tabel 2 terlihat bahwa skor nyeri kelompok kontrol dari 7,95 $\pm 1,76$ turun menjadi $7,60 \pm 1,73$ pada hari ketiga pengobatan. Hal yang sama terjadi pada kelompok intervensi, skor nyeri dari 9,10 $\pm 1,07$ turun menjadi 3,80 $\pm 1,0$. 
Tabel 2. Efektivitas pijat dengan minyak esensial cengkeh terhadap status fungsional pasien OA

\begin{tabular}{|c|c|c|c|c|c|}
\hline WOMAC & $\begin{array}{l}\text { Baseline } \\
\text { (rerata } \pm \text { SD) }\end{array}$ & $\begin{array}{l}\text { Post-test hari } 1 \\
\text { (rerata } \pm \text { SD) }\end{array}$ & $\begin{array}{l}\text { Post-test hari } 2 \\
\text { (rerata } \pm \text { SD) }\end{array}$ & $\begin{array}{l}\text { Post-test hari } 3 \\
\text { (rerata } \pm \mathrm{SD})\end{array}$ & $\begin{array}{l}\text { p-Value within } \\
\text { group }\end{array}$ \\
\hline \multicolumn{6}{|l|}{ Total WOMAC } \\
\hline Kontrol & $40,95 \pm 7,68$ & $40,95 \pm 7,68$ & $40,75 \pm 7,59$ & $40,35 \pm 7,53$ & 1,00 \\
\hline Intervensi & $46,55 \pm 4,71$ & $41,00 \pm 8,00$ & $30,20 \pm 6,99$ & $21,30 \pm 3,36$ & 0,02 \\
\hline $\begin{array}{l}p \text {-Value } \\
\text { between group }\end{array}$ & 0,01 & 0,92 & 0,00 & 0,00 & \\
\hline \multicolumn{6}{|l|}{ Nyeri } \\
\hline Kontrol & $7,95 \pm 1,76$ & $7,95 \pm 1,76$ & $7,75 \pm 1,71$ & $7,60 \pm 1,73$ & 0,00 \\
\hline Intervensi & $9,10 \pm 1,07$ & $8,30 \pm 1,38$ & $6,00 \pm 1,92$ & $3,80 \pm 1,01$ & 0,00 \\
\hline $\begin{array}{l}p \text {-Value } \\
\text { between group }\end{array}$ & 0,02 & 0,54 & 0,00 & 0,00 & \\
\hline \multicolumn{6}{|l|}{ Kekakuan } \\
\hline Kontrol & $4,80 \pm 0,95$ & $4,80 \pm 0.95$ & $4,80 \pm 0.95$ & $4,65 \pm 0.88$ & 0,11 \\
\hline Intervensi & $5,60 \pm 0,68$ & $4,90 \pm 0.97$ & $3,30 \pm 0.86$ & $1,85 \pm 0.75$ & 0,00 \\
\hline $\begin{array}{l}p \text {-Value } \\
\text { between group }\end{array}$ & 0,00 & 0,73 & 0,00 & 0,00 & \\
\hline \multicolumn{6}{|l|}{ Fungsi Fisik } \\
\hline Kontrol & $28,20 \pm 6,09$ & $28,20 \pm 6,09$ & $28,20 \pm 6,09$ & $8,10 \pm 6,16$ & 0,11 \\
\hline Intervensi & $32,00 \pm 3,67$ & $27,80 \pm 6,57$ & $20,90 \pm 4,89$ & $15,65 \pm 2,54$ & 0,00 \\
\hline $\begin{array}{l}p \text {-Value } \\
\text { between group }\end{array}$ & 0,04 & 0,91 & 0,00 & 0,00 & \\
\hline
\end{tabular}

Jadi pasien yang diberikan pijat dengan minyak esensial cengkeh dan pijat dengan minyak kelapa sama-sama mengalami penurunan intensitas nyeri secara signifikan. Hasil yang didapat sejalan dengan penelitian yang dilakukan oleh Yip (2018) bahwa pemberian pijat dengan minyak esensial jahe dan jeruk signifikan $(\mathrm{p}=0,02)$ menurunkan skor intensitas nyeri orang tua yang mengalami nyeri sedang hingga berat pada bagian lutut [17]. Menurut Palupi (2016) bahwa minyak esensial cengkeh memiliki efek farmakologis sebagai anti nyeri dan mampu menurunkan nyeri sendi ekstremitas bawah pada lansia [9]. Efek analgesik eugenol ditimbulkan akibat kemampuannya dalam menghambat prostaglandin dan mediator inflamasi seperti leukotrien serta menghambat reseptor nyeri [18].

Pada outcome kekakuan, skor kekakuan kelompok kontrol tidak signifikan turun $(\mathrm{p}=0,11)$ dari 4,80 $\pm 0,95$ menjadi $4,65 \pm 0,88$ di hari ketiga pengobatan. Hal sebaliknya terjadi pada kelompok intervensi, terjadi signifikan $(\mathrm{p}=0,00)$ penurunan skor kekakuan yang dialami pasien dari semula $5,60 \pm 0,68$ menjadi $1,85 \pm 0,75$ di hari ketiga pengobatan. Penurunan kekakuan signifikan $(p=0,00)$ telah terjadi pada hari kedua setelah diberikan terapi pijat dengan minyak esensial cengkeh. Minyak esensial cengkeh mengandung eugenol sebesar 36-85\%, yang memiliki efek sama dengan gingerol pada jahe. Oleh karena itu penelitian yang dilakukan sejalan dengan penelitian Zakeri et al. (2011) yakni minyak esensial jahe signifikan $(\mathrm{p}<0,05)$ mengurangi kekakuan persendian pada pasien osteoartritis [19]. Pemberian pijat minyak esensial cengkeh dapat memberikan relaksasi pada otot sehingga dapat menstimulasi otot-otot untuk menurunkan kekakuan pada OA [20].

Pada outcome fungsi fisik, skor fungsi fisik kelompok kontrol tidak signifikan turun $(p=0,11)$ 
dari 28,20 \pm 6,09 menjadi 28,10 $\pm 6,16$ di hari ketiga pengobatan. Hal sebaliknya terjadi pada kelompok intervensi, terjadi signifikan $(p=0,00)$ penurunan skor fungsi fisik yang dialami pasien darisemula32,00 $\pm 3,67$ menjadi 15,65 $\pm 2,54$. Hasil yang didapat sejalan dengan penelitian Pehlivan (2019) bahwa pijat 15-20 menit 2 kali seminggu selama 3 minggu dengan minyak esensial black seed signifikan $(\mathrm{p}<0,001)$ menurunkan skor fungsi fisik pasien OA di minggu ke-4 [21]. Selain itu juga efek minyak esensial black seed menurun pada minggu kedelapan. Oleh karena itu diperlukan penelitian lebih lanjut mengenai efektivas pijat dengan minyak esensial cengkeh dalam jangka panjang. Salah satu tanda dan gejala yang muncul akibat kegagalan mekanisme regulator pada osteoartritis adalah keterbatasan fungsi fisik sehingga penderita akan kesulitan untuk menjalankan aktivitas sehari-hari. Pemberian stimulus berupa pijat minyak esensial cengkeh bertujuan untuk membantu mekanisme regulator untuk beradaptasi terhadap perubahan internal tubuh pasien osteoartritis. Stimulasi yang dihasilkan oleh minyak esensial cengkeh dapat mempengaruhi subsistem regulator untuk mengurangi nyeri dan kekakuan pada sendi sehingga dapat memperbaiki fungsi fisik dari OA [22].

Penelitian ini menunjukkan kombinasi pengobatan konvensional dan pijat dengan minyak esensial cengkeh memiliki implikasi yang penting sebagai alternatif pengobatan komplementer pasien OA dengan tingkat nyeri sedang hingga berat. Dengan adanya penelitian ini, tersedia suatu evidence untuk merekomendasikan penggunaan pijat dengan minyal esensial cengkeh dalam mempercepat penurunan nyeri, kekakuan, dan memperbaiki fungsi fisik pasien OA. Terdapat beberapa keunggulan dari penggunaan minyak esensial cengkeh yakni pijat dengan minyak esensial cengkeh merupakan metode yang populer dengan efek samping yang minimal. Selain itu juga pasien bisa melakukan pijat dengan minyak esensial cengkeh seorang diri tanpa bantuan dari tenaga kesehatan. Perlu diingat juga pijat dengan minyak esensial cengkeh harus dihentikan jika pasien mengalami peningkatan rasa nyeri dan otot mengalami inflamasi atau pembengkakan [17].

\section{Keterbatasan Penelitian}

Keterbatasan dari penelitian ini yakni metode yang digunakan hanya sebatas quasi experimental-nonequivalent control group design. Hal tersebut disebabkan sulitnya mengeliminasi kemungkinan bisa akibat adanya confounding variable. Diperlukan desain studi RCT (Randomized Controlled Trial) untuk lebih meyakinkan efektivitas pijat dengan minyak esensial cengkeh terhadap status fungsional pasien OA. Selain itu juga peneliti tidak mengevaluasi efek minyak esensial cengkeh lebih dari tiga hari pengobatan. Tentunya jika hal tersebut dilakukan akan lebih menggambarkan efek pijat dengan minyak esensial dalam jangka panjang bagi penderita OA.

\section{Kesimpulan}

Hasil penelitian menunjukkan bahwa kombinasi pengobatan konvensional dan pijat dengan minyak esensial cengkeh signifikan $(p=0,00)$ menurunkan nyeri, kekakuan, dan meningkatkan fungsi fisik pasien OA dengan nyeri sedang hingga berat. Kelompok yang diberikan pijat dengan minyak kelapa hanya signifikan $(p=0,00)$ menurunkan intensitas nyeri yang dialami oleh pasien OA. Hasil penelitian ini dapat digunakan oleh pasien OA dan dokter dalam merekomendasikan penggunaan pijat dengan minyak esensial cengkeh untuk meningkatkan status fungsional pasien OA.

\section{Ucapan Terima Kasih}

Peneliti menyampaikan ucapan terimakasih kepada Puskesmas I Denpasar Barat yang telah 
memberikan izin untuk dapat melakukan pengambilan data penelitian.

\section{Daftar Pustaka}

1. Almasdy D, Eptiyeni E, Khamri D, Kurniasih N. Use of complementary and alternative medicine (CAM) among breast cancer patients in a public hospital in padang, Indonesia. J Young Pharm. 2018;10(2):145-7.

2. Kementerian Kesehatan RI. Riset Kesehatan Dasar (Riskesdas). Badan Penelitian dan Pengembangan Kesehatan; 2018.

3. Kadir AA. A Review of Complementary and Alternative Medicines for Osteoarthritis. J Complement Med Altern Healthc. 2018;6(4):1-4.

4. Yang L, Sibbritt D, Adams J. A critical review of complementary and alternative medicine use among people with arthritis: a focus upon prevalence, cost, userprofiles, motivation, decision-making, perceived benefits andcommunication. Rheumatology International. 2017;37(3):337-51.

5. Gorial FI, Sabah SA-SA, Kadhim MB, Jamal NB. Functional Status in Knee Osteoarthritis and its Relation to Demographic and Clinical Features. Mediterr J Rheumatol. 2018;29(4):207-10.

6. Yang S, Dubé CE, Eaton CB, McAlindon TE, Lapane KL. Longitudinal use of complementary and alternative medicine among older adults with radiographic knee osteoarthritis. Clin Ther. 2013;35(11):1690-702.

7. Perlman A, Fogerite SG, Glass O, Bechard E, Ali A, Njike VY, et al. Efficacy and Safety of Massage for Osteoarthritis of the Knee: a Randomized Clinical Trial. J Gen Intern Med. 2019;34(3):379-86.

8. Tosun B, Unal N, Yigit D, Can N, Aslan O, Tunay S. Effects of self-knee massage with Ginger Oil in patients with Osteoarthritis: An experimental study. Res Theory Nurs Pract. 2017;31(4):379-92.

9. Palupi NW. Pengaruh Minyak Atsiri Cengkeh Terhadap Penurunan Nyeri Sendi Ekstremitas
Bawah Pada Lansia. J Kesehatan. 2016;3(2).

10. Cen SY, Loy SF, Sletten EG, Mclaine A. The effect of traditional Chinese Therapeutic Massage on individuals with neck pain. Clin Acupunct Orient Med. 2003;4(2-3):88-93.

11. Field T, Hernandez-Reif M, Diego M, Schanberg S, Kuhn C. Cortisol decreases and serotonin and dopamine increase following massage therapy. International Journal of Neuroscience. 2005; 115(10):1397-413.

12. Ernst E. Manual Therapies for Pain Control: Chiropractic and Massage. The Clinical Journal of Pain. 2004;20(1): 8-12.

13. Osborn CE, Barlas P, Baxter GD, Barlow JH. Aromatherapy: A survey of current practice in the management of rheumatic disease symptoms. Complement Ther Med. 2001;9(2):62-7.

14. Portney LG, Watkins MP. Foundations of clinical research:applications to practice. Norwalk, Connecticut: Appleton \&Lange; 2002.

15. Rahimi F, Goli S, Soltani N, Rezaei H, Amouzeshi Z. Effects of Complementary Therapies on Labor Pain: A Literature Review. Mod Care J. 2018;15(1).

16. Antoni A, Pebrianthy L, Harahap DM, Suharto S, Pratama MY. Pengaruh Penggunaan Kompres Kayu Manis terhadap Penurunan Skala Nyeri pada Penderita Arthritis Gout di Wilayah Kerja Puskesmas Batunadua. J Kesehat Glob. 2020;3(1):26-31.

17. Yip YB, Tam ACY. An experimental study on the effectiveness of massage with aromatic ginger and orange essential oil for moderate-to-severe knee pain among the elderly in Hong Kong. Complement Ther Med. 2008;16(3):131-8.

18. Kamkar Asl M, Nazariborun A, Hosseini M. Analgesic effect of the aqueous and ethanolic extracts of clove. Avicenna $J$ phytomedicine. 2013;3(2):186-92.

19. Zakeri Z, Izadi S, Bari Z, Soltani F, Narouie B, Ghasemi M. Evaluating the effects of ginger extract on knee pain, stiffness and difficulty in patients with knee osteoarthritis. Journal of 
Medicinal Plants Research. 2011;5(15):3375-9.

20. Setiani D, Karnasih W. Efektivitas Pemberian Air Rebusan Cengkeh terhadap Penurunan Asam Urat pada Usia Lanjut di Posyandu Lansia RW 06, Blunyahrejo, Tegalrejo, Yogyakarta. 2010.

21. Pehlivan S, Karadakovan A. Effects of aromatherapy massage on pain, functional state, and quality of life in an elderly individual with knee osteoarthritis. Japan J Nurs Sci. 2019;16(4):450-8.

22. Indraswari $P$, Aryanti N. Pengaruh Masase Jahe Merah (Zingiber Officinale Var. Rubrum) Terhadap Nyeri, Kekakuan Sendi dan Keterbatasan Fungsi Fisik pada Lansia dengan Osteoarthritis. 2018 